\title{
Diazoxide-resistant focal hyperinsulinism
}

INSERM

\section{Source}

INSERM. (1999). Orphanet: an online rare disease and orphan drug data base. Diazoxideresistant focal hyperinsulinism. ORPHA:79298

Diazoxide-resistant focal hyperinsulism (DRFH) is a form of diazoxide-resistant hyperinsulinism (see this term) characterized by recurrent episodes of profound hypoglycemia caused by an excessive/ uncontrolled insulin secretion (inappropriate for the level of glycemia) due to a focal adenomatous hyperplasia of pancreas, that is unresponsive to medical treatment with diazoxide, necessitating complete excision of the focal lesion. 